\title{
Effects of Core Stability Exercises, Lumbar Lordosis and Low-Back Pain: A Systematic Review
}

\author{
Gojko Skundric', Veljko Vukicevic ${ }^{1}$, Nikola Lukic ${ }^{1}$ \\ ${ }^{1}$ University of Novi Sad, Faculty of Sport and Physical Education, Novi Sad, Serbia
}

\begin{abstract}
Core stability has a very positive effect on the prevention of lumbar lordosis and lower back pain. The main focus of this paper was on a review of the available literature on the influence of trunk stability on lower back pain and lumbar lordosis. The two electronic databases researched for collecting articles are PubMed and ScienceDirect. A search was conducted by title, taking a predefined combination of the following keywords into account: low back pain, core stability, training, sports. Screening processes are summarized through a PRISMA flow chart. 408 studies were identified, of which 20 met the inclusion criteria. It was concluded that exercise on the stability of the pelvic nucleus and muscles is recommended as the simplest and most favorable prevention of lower back pain and lumbar lordosis. The stability of the nucleus helps to overcome the main causes and deprive the body of functional disorders and pain.
\end{abstract}

Keywords: Low Back Pain, Core Stability, Training, Sports

\section{Introduction}

Lower back pain (LBP) is a growing problem among people around the world, especially in underdeveloped countries, resulting in a very large impact on people's quality of life (Buchbinder et al., 2013; Haryono, Kawilarang, \& Prastowo, 2019). The increase in the impact left by LBP, observed in recent research, shows that LBP is among the ten most significant causes of disability (Collaborators, 2015). It has been noted that the prevalence of LBP by the end of life is found in about $84 \%$, and almost $23 \%$ suffer from constant pain (Airaksinen et al., 2015), but this is very variable and depends on the specifics of the population under study. The economic issue of early retirement and loss of productivity, related to LBP, is alarming due to the high costs for individuals and the state (Buchbinder et al., 2013). Etiology of LBP multiple factor with previous LBP, frequent bending and twisting, prolonged static positions, anxiety, depression and somatization associated with the development of the condition (McIntosh \& Hall, 2008; van Middelkoop et al., 2010) Musculoskeletal risk factors are also associated with LBP and they can be identified and addressed through the potential discovery of a mechanism by which LBP can be successfully cured. Also, the right identification of risk factors of the musculoskeletal system can indicate the mechanism by which the occurrence of LBP can be prevented, as well as lead to a reduction in socio-economic costs.
It has been shown that lumbopelvic-hip muscle dysfunction (muscle core) increases the load on the spine and reduces the stability of the spine with altered patterns of recruitment of basic muscles, which is a sign of LBP, especially in the chronic form (Hodges \& Richardson, 1998). Therefore, abnormal lower limb function is not recommended in order to mitigate the impact force and affect the spinal load with proximal and distal dysfunction in the lower limbs, which contributes to the increase in LBP. Feet that are in increased pronation (Botte, 1981; Builder \& Marr, 1980; Cibulka, 1999) and shortened hind leg muscles (Mierau, Cassidy, \& Yong-Hing, 1989; Kujala, Salminen, Taimela, Oksanen, \& Jaakkola, 1992) affect a high risk of getting LBP. Feet that are in great pronation cause the tibia and femur to rotate inward and lead to APT (anterior pelvic tilt) (Kujala et al., 1992; Khamis \& Yizhar, 2007). When the pelvis is in an altered position, sciatic nerve entrapment can very often occur, because the piriformis muscle is overloaded (Botte, 1981; Cibulka et al., 2010). In addition, it is suggested that the changed position of the pelvis should load the intervertebral discs, increasing the pain (Gurney, 2002; Tateuchi, Wada, \& Ichihashi, 2011). Tight tendon muscles can reduce lumbar lordosis, potentially reducing force absorption and thus increasing the chances of LBP (Alston, Carlson, Feldman, Grimm, \& Gerontinos, 1966).

If there are changes in the curvature of the spine, very often there

Correspondence:

Montenegro V.Vukicevic

Sport University of Novi Sad, Faculty of Sport and Physical Education, 16 Lovcenska str, 21000 Novi Sad, Serbia E-mail: vukicevicveljko9@gmail.com 
are pains in certain parts of the back. Lumbar lordosis is one of the most important parts of the spinal pillar that has special importance due to the unique position and having direct contact with the pelvis. It should be paid special attention to the spine in order to have a good physical condition (Kendall, McCreary, Provance, Rodgers, \& Romani, 2005). In addition to the bones, ligaments, muscles, and disks vertebra have also a key role in lordosis formation. Without muscle action, pelvic girdle performance hasn't sufficient stability (Hodges \& Moseley, 2003). The Central stabilization of the vertebral column is supported by special muscles such as multifidus, transversus abdominis, and internal muscles in trunk. These muscles act late in patients who suffered from hyper lordosis (Wagner, Liebetrau, Schinowski, Wulf, \& de Lussanet, 2012). The muscles provide stability of vertebrae in a focal form (Hodges \& Moseley, 2003). Decreased strength of one of the muscles of the lumbar-pelvic region affects the change in the position of the pelvis, which disturbs the balance of this part of the body (Norris, 2008) and thus a person can be prone to musculoskeletal disorders (Bouchard \& Tetreault, 2000). Biomechanical and clinical studies have shown that muscles can provide stabilization of segments by controlling movement in the neutral zone, and physiological boundaries can be re-established with adequate muscle control (Danneels et al., 2001). Increased lumbar lordosis, if viewed from the mechanical side, is closely related to increased pain in the lower back (von Lackum, 1924; El-Hamalawy, 2011). There are very different factors that cause lumbar lordosis. Some studies have shown that the range of lumbar lordosis is affected by age and sex, movement in the center of mass such as pregnancy or obesity (El-Hamalawy, 2011; Lee, Jung, \& Lee, 2013). Exercise is accepted increasingly popular to correct and refine such deformities. Stabilization of the lumbar-pelvic region is improved by exercise, which affects the correct posture and at the same time improves muscle function (Lee et al., 2013; Kofotolis \& Kellis, 2006). Some studies suggest that people with low back pain should refrain from certain back exercises, instead of focusing on non-specific physical activities that would improve the psychological state and largely eliminate the pain (Hurwitz, Morgenstern, \& Chiao, 2005). This systematic review aimed to identify and point out exercise models that can be applied preventively in a population that may be or is already exposed to problems with lumbar lordosis and lower back pain.

\section{Method}

\section{Literature Search Strategy}

To ensure a transparent and complete report, the Preferred Reporting Items For Systematic Reviews (PRISMA) guidelines were followed for conducting a systematic review (Moher et al., 2009). Two electronic databases explored for article collection were PubMed and ScienceDirect. In each database, a search was conducted by title, taking a predefined combination of the following keywords into account: low back pain, core stability, training, sport. The presentation of the articles was carried out in three steps: reading the title, reading the abstracts, and then reading the entire text. Screening processes are summarized through the PRISMA flow chart shown below in Figure 1.

\section{Inclusion and Exclusion criteria}

Only original articles written in English and published in peer-reviewed journals are considered for inclusion in this review. The publication date limit was from 2011 and is closed until December 2019 in Figure 2.

Various formats of publications such as reviews, abstracts, citations, abstracts of scientific conferences, books, book reviews, editorials, articles, and comments that have not been reviewed, are

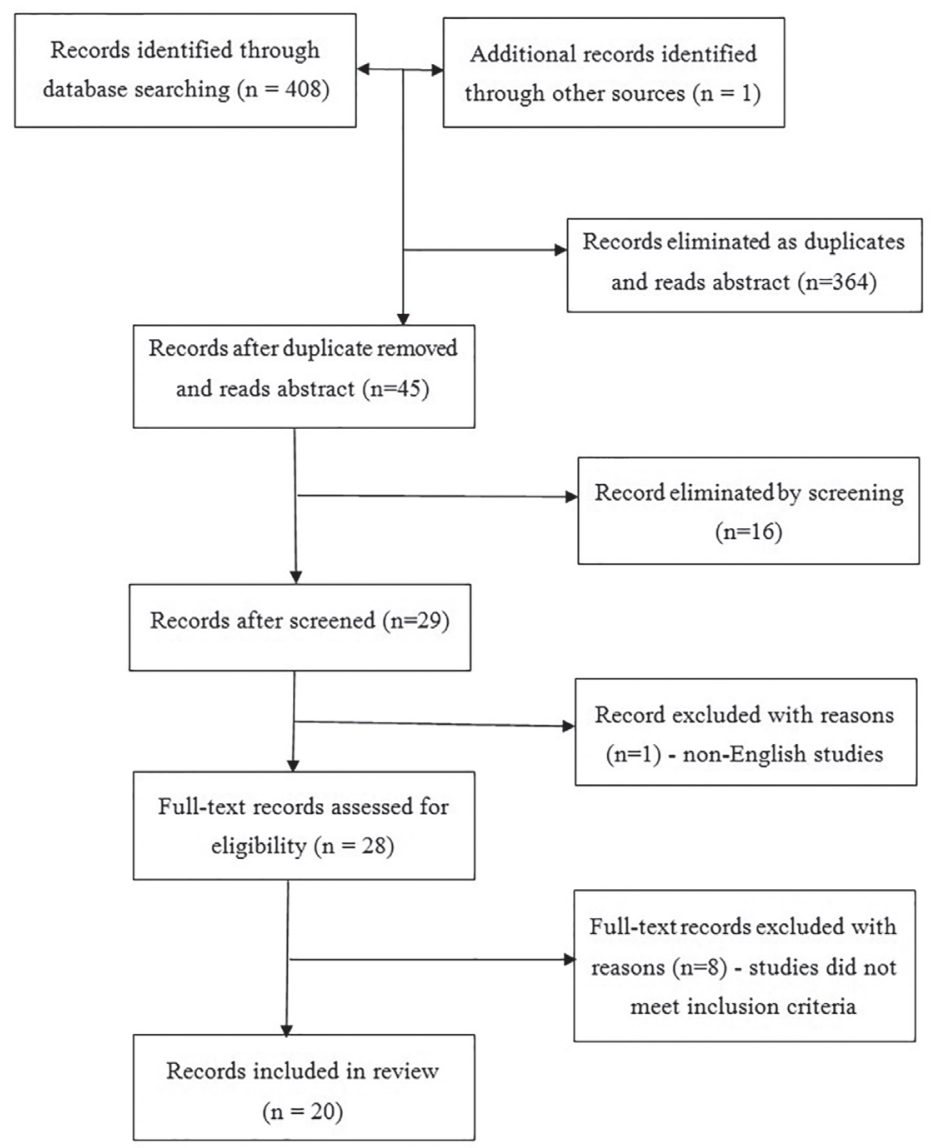

FIGURE 1. PRISMA flow diagram (Moher, et al., 2009). 
excluded. Only the effects of core stability exercises, lumbar lordosis, and lower back pain can be included in the examination. Eligible articles should be conducted with people of all ages. Both qualitative and quantitative articles were taken into account.

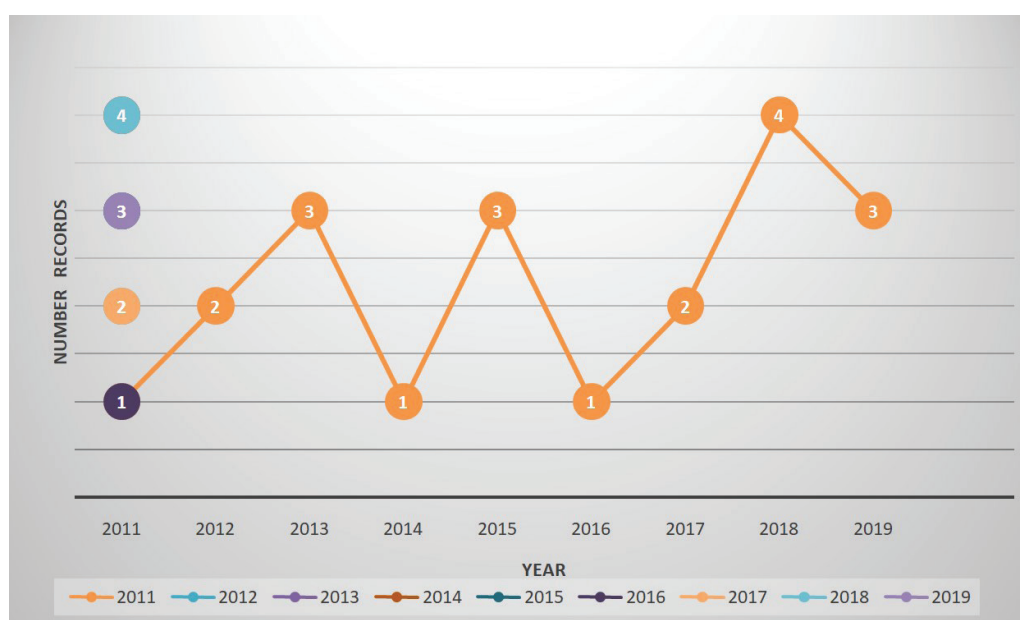

FIGURE 2. Distribution of researches from scientific journals on effects of core stability exercises, lumbar lordosis, and low-back pain

\section{Results}

Preliminary title and the abstract search revealed 408 articles both through PubMed and through ScienceDirect. After reviewing the abstract, 364 duplicates were removed and 45 articles were considered acceptable for further examination. In addition, an article was added to the entire text that was not found during my initial search, but which was considered relevant. This one article was suggested by another researcher, who found them in the appropriate bibliography. Moreover, one other article was removed due to the use of non-English language and without translation. Of the 28 articles analyzed, 8 were excluded from the review due to the insignificance or unavailability of relevant data. Therefore,

Table 2. Study design and characteristics

\begin{tabular}{|c|c|c|c|}
\hline \multirow{2}{*}{ Author } & \multirow{2}{*}{$\begin{array}{c}\text { Number } \\
\text { participants }\end{array}$} & \multicolumn{2}{|c|}{ Effects of core stability exercises, lumbar lordosis, and low-back pain } \\
\hline & & Procedure & Conclusion \\
\hline $\begin{array}{c}\text { Marshall et al. } \\
\text { (2011) }\end{array}$ & 20 & $\begin{array}{l}\text { In this paper, they measured the activity } \\
\text { of trunk muscles in people who had pain } \\
\text { and in people who did not have pain in the } \\
\text { lower back. Muscle activity was measured } \\
\text { during the most commonly used exercises. } \\
\text { Abdominal breathing was also examined as } \\
\text { a possibility of achieving muscle stimulation. } \\
\text { Muscle activity was measured by paired } \\
\text { surface electrodes. }\end{array}$ & $\begin{array}{l}\text { Reduced symptoms of worsening in the test } \\
\text { group indicated that the exercises presented } \\
\text { in this study could be successfully applied in } \\
\text { the recovery of patients with LBP. }\end{array}$ \\
\hline Taanila et al. (2012) & 982 & $\begin{array}{l}\text { In this study, the predictions of LBP in young } \\
\text { soldiers from Finland were investigated, in } \\
\text { relation to their physical preparation. Four } \\
\text { studies were done and monitored over a } \\
\text { period of six months, in soldiers aged } 18-28 \text {. }\end{array}$ & $\begin{array}{c}\text { Soldiers who had reduced strength levels, } \\
\text { reduced levels of aerobic capacity, and those } \\
\text { who had lower levels of education were at } \\
\text { higher risk for LBP. }\end{array}$ \\
\hline $\begin{array}{l}\text { Micheo et al. } \\
\text { (2012) }\end{array}$ & n.d. & $\begin{array}{l}\text { In this paper, it was shown that programmed } \\
\text { work on static flexibility can improve the } \\
\text { amplitude of movements in the joints, but } \\
\text { injuries of the musculoskeletal system cannot } \\
\text { be reduced and muscle performance can } \\
\text { be damaged after stretching. In contrast, } \\
\text { dynamic flexibility has the effect of improving } \\
\text { physical performance and increasing strength. }\end{array}$ & $\begin{array}{c}\text { It has been determined that training for torso } \\
\text { stability increases neuromuscular control } \\
\text { and balance, reduces injuries to the joints of } \\
\text { the lower extremities and pain in the lower } \\
\text { back. }\end{array}$ \\
\hline Teyhen et al. (2013) & 340 & $\begin{array}{l}\text { The aim of this study was to analyze two } \\
\text { programs of work with exercises for body } \\
\text { stabilization. The program was realized in } \\
\text { a military base and lasted for a period of } \\
12 \text { weeks. One exercise program consisted } \\
\text { of motor control exercises (low number } \\
\text { of repetitions and low load) and the other } \\
\text { exercise program was traditional (high } \\
\text { number of repetitions and high load). }\end{array}$ & $\begin{array}{l}\text { A greater increase in trunk muscle endurance } \\
\text { was observed in the first group, but they } \\
\text { could not predict the occurrence of back } \\
\text { pain on that basis. }\end{array}$ \\
\hline
\end{tabular}


(continued from previous page)

\begin{tabular}{ccc}
\hline \multirow{2}{*}{ Author } & Number & Effects of core stability exercises, lumbar lordosis, and low-back pain \\
& participants & Procedure \\
\hline
\end{tabular}

It has been shown that the stretching of the back extensor muscles and the stabilization

Kline et al. (2013)

This paper investigates the effect of a dynamic sling training system at home, which increases strength and reduces back pain and disability.

Nevison et al. (2013)

Yan et al. (2014)

Trampas et al. (2015)

Kliziene et al. (2015)

Calatayud et al. (2015)

Cruz-Diaz et al. (2017)
In this study, they examined how physiotherapy intervention improves pelvic stability in experienced riders when sitting for more than 30 seconds.

This study investigated the effect of Pilates ball exercise in women in late pregnancy (second and third trimesters) who have lumbar back pain. Trainings were held three times a week, lasting 25 to 30 minutes, and a total of twelve weeks.

In this study, individuals with chronic lumbar back pain and an unstable lumbar region were tested. The effect of trunk stability exercises and myofascial trigger point (MTrP) therapy was compared with exercises to stabilize the trunk on dynamic-

balance performance and the crosssectional area of activated muscles and the pain threshold

In this study, the effects of body stabilization exercises in women with back pain and in healthy women were analyzed.

The aim of this study was to investigate muscle activation in balance exercises at various levels, using elastic resistance. The initial positions for balance exercises were sitting, and then the position was changed to standing on both legs. After that, the position changed to one leg. After that, unstable substrates were inserted. Finally, elastic resistance was added to increase the level of activation.

The aim of this study was based on a comparison of special trunk stabilization exercises and basic exercises. The differences were monitored using ultrasound imaging to measure the thickness of the deep stabilizer muscles. The program was realized three times a week, and there were a total of 16 trainings. Muscle thickness was measured before and after treatment.

The aim of this study was to determine which Pilates method gives better results in relieving back pain. The second goal was to activate the transversus abdominis in the rehabilitation process. One group applied the program for 6 weeks and the other for 12 weeks. by exercising, because it is very important of the torso muscles can have a preventive effect on back pain. It has also been noticed that with this method of work, dancers can increase the strength of this part of the body without irritating the sciatic nerve and reducing pain.

They found that moving the pelvic region can reduce pelvic floor muscle asymmetry and increase rider stability. Also, this work

helps in further work on improving the physiotherapeutic intervention (training) for the benefit of riders and horses.

The effects of exercise gave positive results and reduced pain in the lumbar back. Also, this exercise model has been tested on the basis of evidence and can be successfully applied.

Body stabilization exercises immediately increase the pain threshold and, together with myofascial therapy, reduce asymmetry in the pelvic region to a minimum.

The exercise program was supposed to increase neuromuscular control and neutralize multifidus dysfunction. This program also increased the volume of multifidus muscles.

It was observed that the level of activation increased with aggravating balance positions.

After the intervention, muscle hypertrophy was noticed in the group that did the basic exercises, and a significant difference in hypertrophy was noticed only in the right side in relation to the other group. Pain also decreased in both groups and disability, but no significant differences were observed.

Improvement and reduction of pain were observed in both groups. 


\begin{tabular}{cccc}
\hline \multirow{2}{*}{ Author } & $\begin{array}{c}\text { Number } \\
\text { participants }\end{array}$ & Effects of core stability exercises, lumbar lordosis, and low-back pain \\
\cline { 3 - 4 } & & Procedure & Conclusion \\
\hline
\end{tabular}

In this study, the effects of Pilates exercise on the dynamic balance of young people with back pain and on their postural stability were

Lopes et al. (2017) 46

Kuszewski et al. (2018)

Behennah et al. (2018)

Mazloum et al. (2018)

Paris-Alemani et al. (2018) determined. The training lasted 20 minutes a day, for a period of 30 days. The training consisted of 4 exercises: swimming, stretching the legs, pelvic pressure and kneeling in the opposite legal arm with the legs.

In this study, hypotheses were investigated that motor torso control training in subjects with a rigid tendon leads to anterior pelvic tilt and that there is a relationship between anterior pelvic tilt and tendon stiffness. The experimental group had muscle control treatment for two weeks and the other group did not train. The measurement was performed three times.

The aim of this study was to investigate the relationship between strength, balance and endurance of lumbar extensors in persons with lumbar back pain and in persons without pain in this region.

The study examined the relationship between selective Pilates exercises and stretching exercises, how they affect lumbar back pain, lumbar angle and disability. The treatment lasted six weeks. Improvement was observed in groups that did selective Pilates.

In this study, the task was to compare motor control and stability of the lumbar-pelvic region in professional dancers and nondancers.

This study examined the effect of Tai Chi on the treatment of lower back pain in people older than 50 years. The program lasted 12 weeks, three times a week for 60 minutes.

The aim of this study was to determine whether athletes with a groin injury in relation to the injured side have an anterior tilt of the pelvis.
This method of work has given positive results in young people with nonspecific pain in the lumbar back.

Within the experimental group, the level of pelvic stiffness and inclination decreased.

The results indicate that with impaired motor control of the muscles in the lumbar region, pain appears. Thus, strengthening the muscles of this region reduces the dysfunction and relieves pain.

Therefore, it was concluded that muscle activation in the lumbar region plays a significant role in eliminating pain and reducing disability.

It was found that the dancers had better dynamic stability and a greater range of motion by automatic activation of the torso muscles, and thus better motor control.

It was concluded that this training method reduces pain in the lumbar part of the back, but does not affect the proprioception of the lower extremities.

The research determined that the lower anterior inclination of the pelvis was on the injured side in relation to the healthy side. This information can play an important role in the rehabilitation process. a total of 20 studies were included in this review (Marshall, Desai, \& Robbins, 2011; Taanila et al., 2012; Micheo, Baerga, \& Miranda, 2012; Teyhen et al., 2013; Kline, Krauss, Maher, \& Qu, 2013; Nevison \& Timmis, 2013; Yan, Hung, Gau, \& Lin, 2014; Trampas, Mpeneka, Malliou, Godolias, \& Vlachakis, 2015; Kliziene, Sipaviciene, Klizas, \& Imbrasiene, 2015; Calatayud et al., 2015; Shamsi, Sarrafzadeh, Jamshidi, Zarabi, \& Pourahmadi, 2016; Cruz-Díaz, Bergamin, Gobbo, \& Martínez-Amat, 2017; Lopes, et al. 2017; Kuszewski, Gnat, \& Gogola, 2018; Behennah, Conway, Fisher, Osborne, \& Steele, 2018; Mazloum, Sahebozamani, Barati, Nakhaee, \& Rabiei, 2018; Paris-Alemany et al., 2018; Zou et al., 2019; Liu et al., 2019; Van Goeverden, Langhout, Barendrecht, \& Tak, 2019).

In total, data obtained more than 2044 a person on the effects of core stability exercises, lumbar lordosis, and low-back pain that met our inclusion criteria were analyzed shown in Table 2.

\section{Discussion}

Trainers or therapists for all populations suggest basic sta- bility exercises. This model is most often used in torso stability training. For the type of population where torso stability training is the main goal of training (people with chronic LBP), there is still a lack of information on the exercise model to solve the problem. This paper provides information on what training or exercise therapy looks like in groups of people with lower back pain compared to those groups of people who are healthy. There was generally a difference in muscle activity between groups that had problems compared to groups of healthy people, but no identical irregular pattern of movement was observed. These changes may reflect a nervous system strategy to modify the spinal load while maintaining a similar technique to healthy controls. Abdominal breathing very successfully increases the activity of the trunk muscles and reduces their imbalance, through various exercises (Shamsi et al., 2016).

Exercise can also be used as a therapy to reduce pain, reduce the percentage of disability and to restore amnesic muscle function. (Brumitt, Matheson, \& Meira, 2013; Kosmas, Georgiou, Marmara, \& Fotiou, 2019). Decreased endurance and strength of 
the torso muscles indicate impaired or reduced neuromuscular control of the body, indicating inhibition of the lower body muscles, which together affect an increased risk of lower back pain (Huxel Bliven \& Anderson, 2013).

Reduced perception of rapid activation of trunk muscles during certain movements, negatively affects the control of movements, which increases the mobility of the joints of the lower extremities in an increased volume, in order to maintain adequate stability of the body. Increased chances of injury are given by the muscles that connect the mentioned joints and which are delayed with activation (Wilkerson, Giles, \& Seibel, 2012). These results clearly support the core stability concept as an important consideration for preventing core and lower extremity injuries in people.

By reviewing the above research, which determines the impact of the effects of basic stability exercises, lumbar lordosis and lower back pain, we can group several results. First group of researchers analyzed the effects of basic stability exercises and prevention of lower back pain and lumbar lordosis using the Pilates program and additional elastic resistance (Yan et al., 2014; Calatayud et al., 2015; Cruz-Diaz et al., 2017; Lopes et al., 2017; Behennah et al., 2018). Based on the results, they were able to plan new projects to prevent LPB and improve the quality of life. Second group of authors dealt with the analysis of programmed training, which was realized over a longer period of time (several months) in the army. Very positive results have appeared after the implemented programs and this type of health prevention in soldiers can be recommended as a cheap way to improve physical fitness Micheo et al., 2012; Teyhen et al., 2013). Third group of authors analyzed the influence of Chinese methods of practicing Tai Chi Chuan and Tai Chi on the prevention of lower back pain (Zou et al., 2019; Liu et al., 2019). Based on core stability testing and APT, a group of authors analyzed lower back pain and lumbar lordosis (Marshall et al., 2011; Trampas et al., 2015; Kliziene et al., 2015; Shamsi et al., 2016; Kuszewski et al., 2018; Behennah et al., 2018; Liu et al., 2019). Fourth group of researchers analyzed the effects of basic stability exercises and prevention of lower back pain and lumbar lordosis in dancers and horse riders (Kline et al., 2013; Nevison \& Timmis, 2013; Paris-Alemany et al., 2018). Other works refer to the classical research of the relationship between the stability of the nucleus and pain in the lower part.

\section{Conclusion}

The paper identifies the evaluation of the effectiveness of including the effects of basic core stability exercises in the prevention of lumbar lordosis and lower back pain. Different analyzes were compared between people who have lower back pain and people who are painless. It has been determined that by improving the stability of the core and pelvic muscles, regular exercise can improve and eliminate pain in the lower back. The main reasons for the mentioned problems and pains are muscular inactivity in certain parts of the body, which could have arisen in various ways. This was shown not only by the results and analyzes when the intervention and control groups were compared, but also by different professions of people.

These results provide an opportunity to recommend exercise on the stability of the pelvic nucleus and muscles as the simplest and most favorable prevention for lower back pain and lumbar lordosis. The stability of the nucleus helps to overcome the main causes and deprive the body of functional disabilities and pain. Prevention programs based on regular physical activities related to strengthening the stability of the nucleus and pelvic muscles are one of the most effective ways to improve and maintain quality of life, which results in diagnosing activities, mobility, ability to function normally without pain.
Acknowledgments

There are no acknowledgements.

\section{Conflict of Interest}

The authors declare that there is no conflict of interest.

Received: 19 July 2020 | Accepted: 14 November 2020 | Published: 18 January 2021

\section{References}

Airaksinen, O., Brox, J.I., Cedraschi, C., Hildebrandt, J., Klaber-Moffett, J., ... Kovacs, F. (2006). Chapter 4 European guidelines for the management of chronic nonspecific low back pain. European Spine Journal, 15(S2), s192-s300. doi:10.1007/s00586-006-1072-1

Alston, W., Carlson, C.E., Feldman, D.J., Grimm, Z., \& Gerontinos, E. (1966). A quantitative study of muscle factors in the chronic low back syndrome. Journal of the American Geriatrics Society, 14(10), 1041-1047.

Barwick, A., Smith, J., \& Chuter, V. (2012). The relationship between foot motion and lumbopelvic-hip function: a review of the literature. The Foot, 22(3), 224-231.

Behennah, J., Conway, R., Fisher, J., Osborne, N., \& Steele, J. (2018). The relationship between balance performance, lumbar extension strength, trunk extension endurance, and pain in participants with chronic low back pain, and those without. Clinical Biomechanics, 53, 22-30.

Botte, R.R. (1981). An interpretation of the pronation syndrome and foot types of patients with low back pain. Journal of the American Podiatry Association, 71(5), 243-253.

Bouchard, S., \& Tetreault, M. (2000). The Motor development of blind people. The Journal of Visual Impairment \& Blindness, 105, 8-10.

Brumitt, J., Matheson, J.W., \& Meira, E.P. (2013). Core stabilization exercise prescription, part I: current concepts in assessment and intervention. Sports Health, 5(6), 504-509.

Buchbinder, R., Blyth, F.M., March, M.L., Brooks, P., Woolf, A.D., \& Hoy, D.G. (2013). Placing the global burden of low back pain in context. Best Practice \& Research Clinical Rheumatology, 27(5), 575-589.

Builder, M.A., \& Marr, S.J. (1980). Case history of a patient with low back pain and cavus feet. Journal of the American Podiatry Association, 70(6), 299-301.

Calatayud, J., Borreani, S., Martin, J., Martin, F., Flandez, J., \& Colado, J.C. (2015). Core muscle activity in a series of balance exercises with different stability conditions. Gait \& Posture, 42(2), 186-192.

Cibulka, M.T. (1999). Low back pain and its relation to the hip and foot. The Journal of orthopaedic sports physical therapy, 29(10), 595-601.

Cibulka, M.T., Strube, M.J., Meier, D., Selsor, M., Wheatley, C., Wilson, N.G., \& Irrgang, J.J. (2010). Symmetrical and asymmetrical hip rotation and its relationship to hip rotator muscle strength. Clinical Biomechanics (Bristol, Avon), 25(1), 56-62.

Collaborators, G.B. (2015). Global, regional, and national incidence, prevalence, and years lived with disability for 301 acute and chronic diseases and injuries in 188 countries, 1990-2013: a systematic analysis for the Global Burden of Disease Study 2013. The Lancet, 386(9995), 743-800.

Cruz-Díaz, D., Bergamin, M., Gobbo, S., \& Martínez-Amat, A. (2017). Comparative effects of 12 weeks of equipment based and mat Pilates in patients with Chronic Low Back Pain on pain, function and transversus abdominis activation. A randomized controlled trial. Complementary Therapies in Medicine, 33, 72-77.

Danneels, L., Vanderstraeten, G., Cambier, D., Witvrouw, E., Bourgois, J., Dankaerts, W., \& De Cuyper, H. J. (2001). Effects of three different training modalities on the cross sectional area of the lumbar multifidus muscle in patients with chronic low back pain. British Journal of Sports Medicine, 35(3), 186-191.

El-Hamalawy, F.A. (2011). A Newly Developed Exercise Program for Treatment of Mechanical Low Back Pain Associated with Accentuated Lumbar Lordosis. Journal of American Science, 7(8), 58-70.

Gurney, B. (2002). Leg length discrepancy. Gait \& Posture, 15(2), 195-206.

Haryono, I. R., Kawilarang, M., \& Prastowo, N. A. (2019). Leg length discrepancy in college students and its association with low back pain: a preliminary study. Journal of Anthropology of Sport and Physical Education, 3(2), 15-18.

Hodges, P.W., \& Moseley, G.L. (2003). Pain and motor control of the lumbopelvic region: effect and possible mechanisms. Journal of Electromyography and Kinesiology, 13(4), 361-370.

Hodges, P.W., \& Richardson, C.A. (1998). Delayed postural contraction of transversus abdominis in low back pain associated with movement of the lower limb. Journal of spinal disorders, 11(1), 46-56.

Hurwitz, E.L., Morgenstern, H., \& Chiao, C. (2005). Effects of Recreational Physical Activity and Back Exercises on Low Back Pain and Psychological Distress: Findings From the UCLA Low Back Pain Study. American journal 
of public health, 95(10), 1817-1824

Huxel Bliven, K.C., \& Anderson, B.E. (2013). Core Stability Training for Injury Prevention. Sports Health, 5(6), 514-522.

Kendall, F.P., McCreary, E.K., Provance, P.G., Rodgers, M.M., \& Romani, W.A. (2005). Muscles Testing and Function with Posture and Pain. 5th Edition. Baltimore, MD: Lippincott Williams \& Wilkins.

Khamis, S., \& Yizhar, Z. (2007). Effect of feet hyperpronation on pelvic alignment in a standing position. Gait \& Posture, 25(1), 127-134.

Kline, J.B., Krauss, J.R., Maher, S.F., \& Qu, X. (2013). Core strength training using a combination of home exercises and a dynamic sling system fo the management of low back pain in pre-professional ballet dancers: a case series. Journal of dance medicine \& science, 17(1), 24-33.

Kliziene, I., Sipaviciene, S., Klizas, S., \& Imbrasiene, D. (2015). Effects of core stability exercises on multifidus muscles in healthy women and women with chronic low-back pain. Journal of Back and Musculoskeletal Rehabilitation, 28(4), 841-847.

Kofotolis, N., \& Kellis, E. (2006). Effects of two 4-week proprioceptive neuromuscular facilitation programs on muscle endurance, flexibility, and functional performance in women with chronic low back pain. Physical therapy, 86(7), 1001-1012.

Kosmas, J., Georgiou, Y., Marmara, E., \& Fotiou, A. (2019). Evaluation of municipal fitness programs for women with low back pain. Journal of Anthropology of Sport and Physical Education, 3(4), 33-39.

Kujala, U.M., Salminen , J.J., Taimela , S., Oksanen , A., \& Jaakkola, L. (1992). Subject characteristics and low back pain in young athletes and nonathletes. Medicine \& Science in Sports \& Exercise, 24(6), 627-632.

Kuszewski, M.T., Gnat, R., \& Gogola, A. (2018). The impact of core muscles training on the range of anterior pelvic tilt in subjects with increased stiffness of the hamstrings. Human movement science, 57, 32-39.

Lee, S.-K., Jung, J.-M., \& Lee, S.-Y. (2013). Gluteus medius muscle activation on stance phase according to various vertical load. Journal of Back and Musculoskeletal Rehabilitation, 26(2), 159-161.

Liu, J., Yeung, A., Xiao, T., Tian, X., Kong, Z., Zou, L., \& Wang, X. (2019). ChenStyle Tai Chi for Individuals (Aged 50 Years Old or Above) with Chronic Non-Specific Low Back Pain: A Randomized Controlled Trial. International Journal of Environmental Research and Public Health, 16(3), 517.

Lopes, S., Correia, C., Félix, G., Lopes, M., Cruz, A., \& Ribeiro, F. (2017). Immediate effects of Pilates based therapeutic exercise on postural control of young individuals with non-specific low back pain: A randomized controlled trial. Complementary Therapies in Medicine, 34, 104-110.

Marshall, P.W., Desai, I., \& Robbins, D.W. (2011). Core stability exercises in individuals with and without chronic nonspecific low back pain. Journal of strength and conditioning research, 25(12), 3404-3411.

Mazloum, V., Sahebozamani, M., Barati, A., Nakhaee, N., \& Rabiei, P. (2018) The effects of selective Pilates versus extension-based exercises on rehabilitation of low back pain. Journal of bodywork and movement therapies, 22(4), 999-1003.

Mclntosh, G., \& Hall, H. (2008). Low back pain (chronic). BMJ clinical evidence, 1116.

Micheo, W., Baerga, L., \& Miranda, G. (2012). Basic principles regarding strength, flexibility, and stability exercises. $P M \& R$ : The Journal of Injury, Function and Rehabilitation, 4(11), 805-811.

Mierau, D., Cassidy, J.D., \& Yong-Hing, K. (1989). Low-back pain and straight leg raising in children and adolescents. Spine (Phila Pa 1976), 14(5), 526528.

Moher, D., Liberati, A., Tetzlaff, J., Altman, D.G., \& PRISMA Group. (2009). Preferred reporting items for systematic reviews and meta-analyses: the
PRISMA statement. Annals of internal medicine, 151(4), 264-269.

Nevison, C.M., \& Timmis, M.A. (2013). The effect of physiotherapy intervention to the pelvic region of experienced riders on seated postural stability and the symmetry of pressure distribution to the saddle: A preliminary study. Journal of Veterinary Behavior: Clinical Applications and Research, 8(4), 261-264

Norris, C.M. (2008). Back Stability: Integrating Science and Therapy. Champaign, Il: Human Kinetics.

Paris-Alemany, A., Torres-Palomino, A., Marino, L., Calvo-Lobo, C., Gadea-Mateos, L., \& La Touche, R. (2018). Comparison of lumbopelvic and dynamic stability between dancers and non-dancers. Physical Therapy in Sport, 33, 33-39.

Shamsi, M., Sarrafzadeh, J., Jamshidi, A., Zarabi, V., \& Pourahmadi, M.R. (2016) The effect of core stability and general exercise on abdominal muscle thickness in non-specific chronic low back pain using ultrasound imaging. Physiotherapy theory and practice, 32(4), 277-283.

Shirado, O., Doi, T., Akai, M., Hoshino, Y., Fujino, K., Hayashi, K., ... Iwaya, T. (2010). Multicenter Randomized Controlled Trial to Evaluate the Effect of Home-Based Exercise on Patients With Chronic Low Back Pain. Spine, 35(17), E811-E819. doi:10.1097/brs.0b013e3181d7a4d2

Taanila, H.P., Suni, J.H., Pihlajamäki, H.K., Mattila, V.M., Ohrankämmen, O., Vuorinen, P., \& Parkkari, J.P. (2012). Predictors of low back pain in physically active conscripts with special emphasis on muscular fitness. The Spine journal, 12(9), 737-748.

Tateuchi, H., Wada, O., \& Ichihashi, N. (2011). Effects of calcaneal eversion on three-dimensional kinematics of the hip, pelvis and thorax in unilateral weight bearing. Human Movement Science, 30(3), 566-573.

Teyhen, D.S., Childs, J.D., Dugan, J.L., Wright, A.C., Sorge, J.A., Mello, J.L., . . George, S.Z. (2013). Effect of Two Different Exercise Regimens on Trunk Muscle Morphometry and Endurance in Soldiers in Training. Physical Therapy, 93(9), 1211-1224.

Trampas, A., Mpeneka, A., Malliou, V., Godolias, G., \& Vlachakis, P. (2015). Immediate Effects of Core-Stability Exercises and Clinical Massage on Dynamic-Balance Performance of Patients With Chronic Specific Low Back Pain. journal of sport rehabilitation, 24(4), 373-383.

Van Goeverden, W., Langhout, R.H., Barendrecht, M., \& Tak, I.R. (2019). Active pelvic tilt is reduced in athletes with groin injury; a case-controlled study. Physical Therapy in Sport, 36, 14-21.

van Middelkoop, M., Rubinstein, S.M., Verhagen, A.P., Ostelo, R.W., Koes, B.W. \& van Tulder, M.W. (2010). Exercise therapy for chronic nonspecific lowback pain. Best Practice \& Research Clinical Rheumatology, 24(2), 193-204.

von Lackum, H.L. (1924). The lumbosacral region. Journal of American Medical Association, 82, 1109.

Wagner, H., Liebetrau, A., Schinowski, D., Wulf, T., \& de Lussanet, M.H. (2012). Spinal lordosis optimizes the requirements for a stable erect posture. Theoretical biology \& medical modelling, 9, 13.

Wilkerson, G.B., Giles, J.L., \& Seibel, D.K. (2012). Prediction of core and lower extremity strains and sprains in collegiate football players: a preliminary study. Journal of atletic training, 47(3), 264-272.

Yan, C.-F., Hung, Y.-C., Gau, M.-L., \& Lin, K.-C. (2014). Effects of a stability ball exercise programme on low back pain and daily life interference during pregnancy. Midwifery, 30(4), 412-419.

Zou, L., Zhang, Y., Liu, Y., Tian, X., Xiao, T., Liu, X.,... Yang, Q (2019). The Effects of Tai Chi Chuan Versus Core Stability Training on Lower-Limb Neuromuscular Function in Aging Individuals with Non-Specific Chronic Lower Back Pain. Medicina (Kaunas), 55(3), 60. 